\title{
National Cancer Institute of Canada
}

National Cancer Institute

\section{Source}

National Cancer Institute. National Cancer Institute of Canada. NCI Thesaurus. Code C25582.

Acts in concert with its partner the Canadian Cancer Society, and with The Terry Fox Foundation, to provide support for cancer research and related programs undertaken at Canadian universities, hospitals and other research institutions. (www.ncic.cancer.ca) 